\title{
Process for Calcium Retention During Skim Milk Ultrafiltration
}

\author{
H. K. Vyas and P. S. Tong \\ Dairy Products Technology Center, \\ California Polytechnic State University, San Luis Obispo 93405
}

\section{ABSTRACT}

Lactose is separated from milk or other fluid dairy products for a variety of reasons. Ultrafiltration is a known process of removing lactose from these products. However, during ultrafiltration, valuable minerals, such as calcium in soluble form, are also lost into permeate. In this study, a process was developed in which first the lactose reduction in skim milk was achieved by ultrafiltration ( $4 \times$ volumetric concentration) using a $10-\mathrm{kDa}$ membrane. Then, the calcium present in permeate was precipitated using one of three methods: 1) heat treatment, 2) $\mathrm{pH}$ adjustment, or 3) a combination of $\mathrm{pH}$ adjustment and heat treatment to permeate, then recovered by refiltering permeate. The process was first developed at laboratory scale, and then its applicability was tested at the pilot scale. Skim milk, retentates, permeates, and the treated permeates were analyzed for total solids, ash, protein, or total nitrogen, calcium, and lactose content. About $76 \%$ of the total lactose and about $16 \%$ of the calcium present in skim milk permeated through the membrane during ultrafiltration. The three treatments applied produced white precipitates and turned the clear permeates turbid. On refiltering the treated permeates $\sim 42, \sim 50$, and $\sim 70 \%$ of the total calcium present could be recovered from 1) heat-treated, 2) $\mathrm{pH}$ adjusted, and 3) $\mathrm{pH}$-adjusted and heat-treated permeates, respectively. There was no marked change in the lactose content due to any of the three treatments and subsequent refiltering of the treated permeates.

(Key words: ultrafiltration, calcium retention, lactose reduction, pilot-scale process)

\section{INTRODUCTION}

Lactose is removed from the fluid milk products to improve its functionality, storage stability, and to make reduced lactose products for consumers (Tory and Sharp, 1930; Tumerman et al., 1954; Silva et al.,

Received March 26, 2002.

Accepted March 24, 2003.

Corresponding author: H. K. Vyas; e-mail: harit_vyas@ hotmail.com.
1984; Martley and Crow, 1993). There are three main known methods of lactose separation. Lactose can be hydrolyzed from milk or fluid milk products and whey using enzymes into glucose and galactose. This is a very effective way of reducing lactose content. However, the hydrolysis only changes the form of sugar present and, therefore, also increases the sweetness (Mahoney, 1992). This can be advantageous or otherwise depending on the purpose of lactose reduction. Alternatively, lactose can be separated by crystallization. However, this is a method of lactose recovery rather than lactose reduction, and its applicability is limited to byproducts such as whey or milk/whey ultrafiltration permeate. Ultrafiltration itself is a very useful process for producing reduced lactose dairy products (Kosikowski, 1979; Edelsten et al., 1983; Patel et al. 1991). Although lactose is never completely removed, diafiltration aids the lactose removal by ultrafiltration. Ultrafiltration membrane retains all the fat globules and milk proteins and allows lactose to permeate. Thus it removes the sugar rather than breaking it into other kinds of sugar. However, ultrafiltration also removes water and soluble minerals. Thus lactose cannot be removed without concentrating the product and also without losing some valuable minerals like calcium.

Minerals including calcium can be separated from whey or milk by processes like electrodialysis, ionexchange, and nanofiltration (Cheryan, 1986) or by adding chelating agents such as EDTA and citrates. Heating or increasing the $\mathrm{pH}$ of milk or whey causes formation of calcium complex or precipitates (Ramchandra Rao, 1995; Vasiljevic and Jelen, 1999). This can be used to retain the soluble calcium during ultrafiltration. However, heating or $\mathrm{pH}$ adjustment of milk or whey alters the state of proteins present and can also cause interactions of protein with proteins and other components.

In this study, the possibility of recovering calcium from the ultrafiltration permeate of skim milk using different methods of precipitation ( $\mathrm{pH}$ adjustment, heat treatment and a combination of both) is explored. Based on these methods, a process is presented to recover calcium lost during lactose reduction of fluid dairy products by ultrafiltration. 


\section{MATERIALS AND METHODS}

\section{Feed}

Fresh pasteurized skim milk was used for laboratory-scale experiments. Skim milk for the pilot-scale experiments was prepared by reconstituting the low heat skim milk powder using deionized water at $10 \%$ (wt/vol) and storing overnight at $<10^{\circ} \mathrm{C}$. Skim milk samples were collected for the analyses.

\section{Processing Conditions}

A stirred cell (Amicon ultrafiltration cell, model 8050, Amicon Div., Danvers, MA) with $10-\mathrm{kDa}$ flat sheet polyethersulfone membrane (Millipore Corp., Bedford, MA) was used for the laboratory-scale ultrafiltration experiments. For each laboratory-scale experimental run, $50 \mathrm{ml}$ of skim milk at $10^{\circ} \mathrm{C}$ was placed in the stirred cell. Filtration was done at $200-\mathrm{kPa}$ applied pressure and the stirring bar speed was set at approximately $50 \mathrm{rpm}$. Filtration was continued until the $4 \times$ concentration (i.e., one fourth of the original volume of skim milk) was achieved. In the first experiments, permeate was collected and heat treated at $63^{\circ} \mathrm{C}$ for 30 min using a water bath. The treated permeate was then refiltered using a clean $10-\mathrm{kDa}$ membrane. In the second experiments, the obtained permeate was adjusted to $\mathrm{pH} 8.0$ using $0.1 \mathrm{~N} \mathrm{NaOH}$. The treated permeate was then refiltered after about $5 \mathrm{~min}$. In third experiments, the obtained permeate was first adjusted to $\mathrm{pH} 8.0$ and then heat-treated at $63^{\circ} \mathrm{C}$ for $30 \mathrm{~min}$. The treated permeate was then refiltered. Samples of the permeates, treated permeates, and treated and refiltered permeates were collected for the analyses. Three replications of each experiment were done. All the experimental runs were done using the same lot of skim milk.

A cross-flow unit (DDS-UF plant, Nakskov, Denmark) as shown in Figure 1 with a $10-\mathrm{kDa}$ spiral wound module was used for the pilot-scale experiments. Filtration was done at $200-\mathrm{kPa}$ transmembrane pressure difference and $2.45 \mathrm{Ls}^{-1}$ flow rate. For each experimental run, $40 \mathrm{~L}$ of reconstituted skim milk was concentrated to $4 \times$ level. The resultant permeate was divided into three equal parts $(10 \mathrm{~L}$ each) for the three different treatments of calcium precipitations. All other experimental conditions were the same as described for the laboratory-scale experiments. Each experiment was carried out in duplicate. A flow chart of the process used at the laboratory as well as pilot scale is shown in Figure 2.

\section{Analytical Methods}

Skim milk and retentates were analyzed for total solids, fat, protein, ash, calcium, and lactose content.

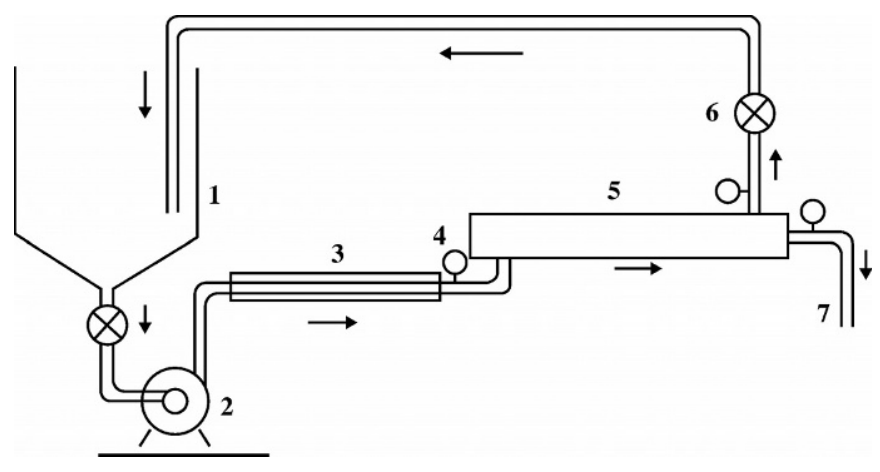

Figure 1. Schematic of the cross-flow ultrafiltration unit used for the pilot-scale experiments: 1) feed tank, 2) centrifugal pump, 3) heat exchanger, 4) pressure gauges at the inlet, outlet, and permeate side of the membrane, 5) membrane module, 6 ) back pressure regulating valve, and 7) permeate outlet.

All the permeates and the treated permeates after refiltration were analyzed for total solids, ash, total nitrogen, calcium, and lactose content. Permeates were also analyzed for the presence of proteins due to any membrane leakage. Treated permeates before reultrafiltration were analyzed for their particle size distribution using laser diffraction type particle size analyzer (model LS230, Coulter Corporation, Miami, FL). Fat content was determined by the Babcock

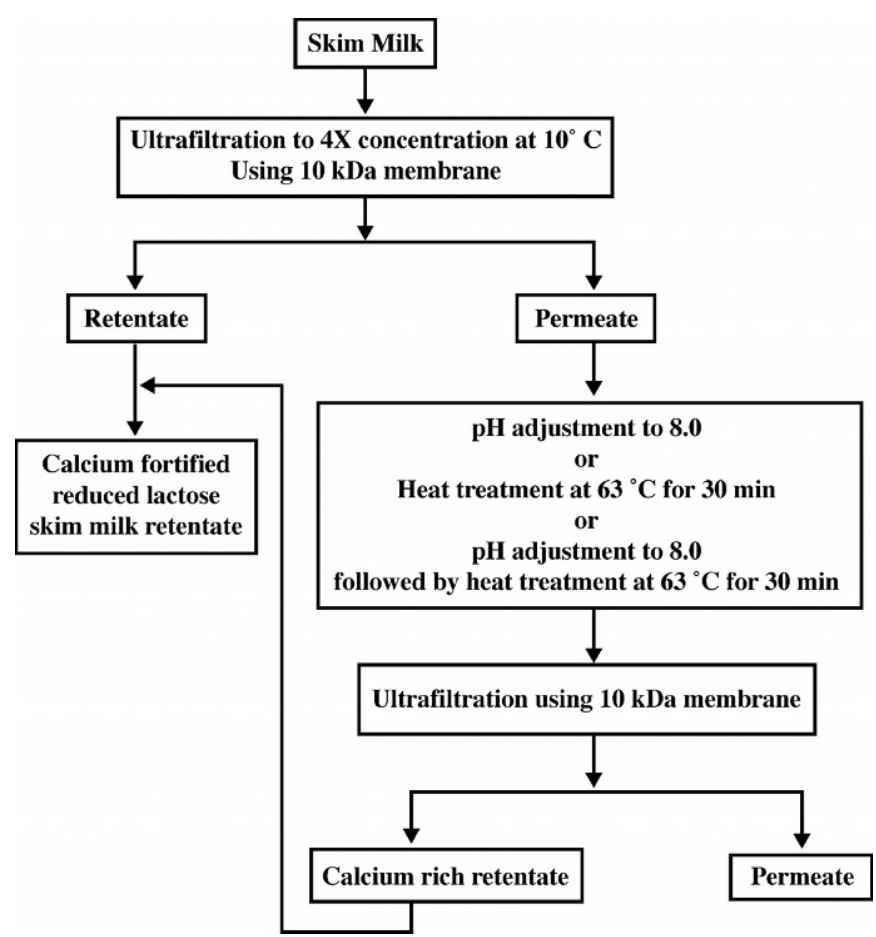

Figure 2. Flow diagram showing different steps of the process followed for the laboratory- and pilot-scale experiments. 
Table 1. Gross composition of the skim milks used for the experiments.

\begin{tabular}{lcc}
\hline Constituent $(\%)$ & Fresh skim milk & $\begin{array}{l}\text { Reconstituted } \\
\text { skim milk }\end{array}$ \\
\hline Total solids & $9.02 \pm 0.02$ & $9.65 \pm 0.04$ \\
Fat & $0.08 \pm 0.01$ & $0.11 \pm 0.01$ \\
Protein & $3.52 \pm 0.11$ & $3.61 \pm 0.12$ \\
Ash & $0.67 \pm 0.01$ & $0.69 \pm 0.01$ \\
Lactose (monohydrate) & $4.41 \pm 0.12$ & $4.65 \pm 0.01$ \\
Calcium (mg/L) & $1209 \pm 1.5$ & $1198 \pm 12$ \\
Others (by difference) & $0.34 \pm 0.18$ & $0.59 \pm 0.12$ \\
\hline
\end{tabular}

method. Total solids and ash were determined by standard gravimetric methods and total nitrogen and protein by Kjeldahl method. The presence of proteins in permeates was checked by $15 \%$ SDS-PAGE. For this, permeate without dilution was mixed with sample buffer at 1:1 proportion. Calcium content of the samples was determined using atomic absorption spectrophotometer (Perkin-Elmer, model 3030B, Norwalk, CT) (Brooks et al. 1970). Lactose content was determined by UV method involving enzymatic hydrolyses (Kleyn and Trout, 1984). Each analysis was done in duplicate and the results averaged.

\section{RESULTS AND DISCUSSION}

The gross composition of the skim milks used for the experiments is shown in Table 1 . In cow milk about $800 \mathrm{mg} \mathrm{L}^{-1}$ of the total calcium is bound to casein micelles and about $370 \mathrm{mg} \mathrm{L}^{-1}$ is soluble or free calcium (Walstra and Jenness, 1984). The total calcium levels detected in the skim milks of this study (Table 1) were similar to that reported value in the literature.

The average composition of permeates for both laboratory-scale and pilot-scale experiments are shown in Table 2. Clear permeates were obtained during ultrafiltration of skim milk. A $10-\mathrm{kDa}$ membrane is expected to allow permeation of only lactose, soluble minerals, and water from the different constituents of milk. The analyses of the permeates revealed that about $76 \%$ of the total lactose present permeated through the membrane when the skim milk was concentrated to $4 \times$ level. About $16 \%$ of total calcium pres-

Table 2. Average composition of the permeates.

\begin{tabular}{lcc}
\hline Constituent $(\%)$ & $\begin{array}{l}\text { Permeates from } \\
\text { stirred cell }\end{array}$ & $\begin{array}{c}\text { Permeates from } \\
\text { crossflow unit }\end{array}$ \\
\hline Total solids & $5.43 \pm 0.02$ & $5.49 \pm 0.04$ \\
Total nitrogen & $0.033 \pm 0.001$ & $0.037 \pm 0.002$ \\
Ash & $0.44 \pm 0.07$ & $0.46 \pm 0.01$ \\
Lactose (monohydrate) & $4.45 \pm 0.05$ & $4.60 \pm 0.04$ \\
Calcium (mg/L) & $249.4 \pm 1.9$ & $251.5 \pm 1.9$ \\
Others (by difference) & $0.503 \pm 0.06$ & $0.393 \pm 0.01$ \\
\hline
\end{tabular}

ent in skim milk also permeated through during the experiments. Considering that about $33 \%$ of the total calcium in cow's milk is soluble or free (Walstra and Jenness, 1984), it can be stated that about $46 \%$ of the total soluble calcium in skim milk permeated through the ultrafiltration membrane during the experiments. Overall, about $50 \%$ of the total minerals in skim milk permeated through. The balance of lactose and minerals (including calcium) originally present in the milk was confirmed when retentate samples were analyzed and mass balance performed. Retentates after $4 \times$ concentration contained $38.7 \mathrm{~g} \mathrm{~L}^{-1}$ of lactose and $4063 \mathrm{~g}$ $\mathrm{L}^{-1}$ of calcium. Similar levels of permeation for lactose calcium and other minerals during ultrafiltration of pasteurized skim milk can be found in other reports, too (Premaratne and Cousin, 1991; St-Gelais et al., 1992). No protein was detected in any of the permeate samples by SDS-PAGE. However, some nitrogen was detected in the samples, as shown in Table 2. This is likely nonprotein nitrogen compound, such as urea or very low molecular weight peptides or free amino acids not detected in SDS-PAGE.

When the permeates were treated by 1 ) heating at $63^{\circ} \mathrm{C}$ for $\left.30 \mathrm{~min}, 2\right) \mathrm{pH}$ adjustment to 8.0 , or 3 ) a combination of the two, precipitates were formed and the permeates turned turbid. The particle size distributions of treated permeates are shown in Figure 3. In all three treatments, particles were in the range of $\sim 0.08$ to $\sim 300 \mu \mathrm{m}$. The overall particle size was largest for the permeates treated with a combination of $\mathrm{pH}$ adjustment and heating. This was followed by the $\mathrm{pH}$ adjusted permeates. The heat-treated permeates had the smallest overall particle size. The treated permeates containing precipitates could be very easily and rapidly refiltered by a clean $10-\mathrm{kDa}$ membrane without causing any marked fouling, and no marked drop in permeate flux was noticed. The permeates resulting from the refiltration step were once again very clear, suggesting that the particles present were retained by the membrane. Although ultrafiltration was used in the present study, considering the observed size ranges of the precipitates found in the treated permeates, even microfiltration may be sufficient for the refiltration step.

The change in the calcium concentration with the treatment to the permeates for the laboratory-scale experiments is shown in Figure 4. The calcium concentration in the permeates decreased after treatment and refiltration, suggesting the retention of calcium by the membrane. Maximum calcium retention was achieved for the permeates that were adjusted to $\mathrm{pH}$ 8.0 and then heat treated. About $70 \%$ of the calcium present in the permeates was recovered. This was followed by $\sim 50$ and $\sim 42 \%$ calcium retention in the case of 


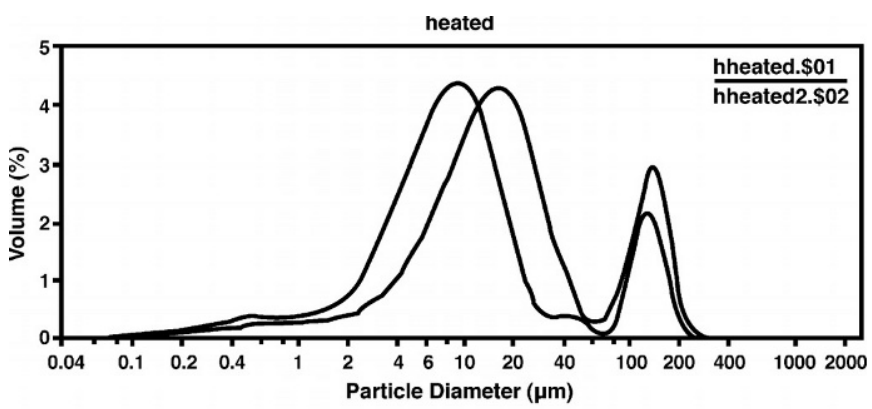

(a)

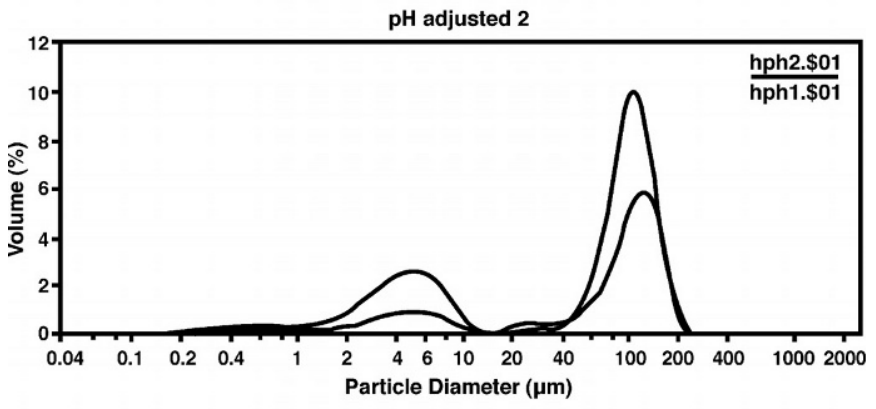

(b)

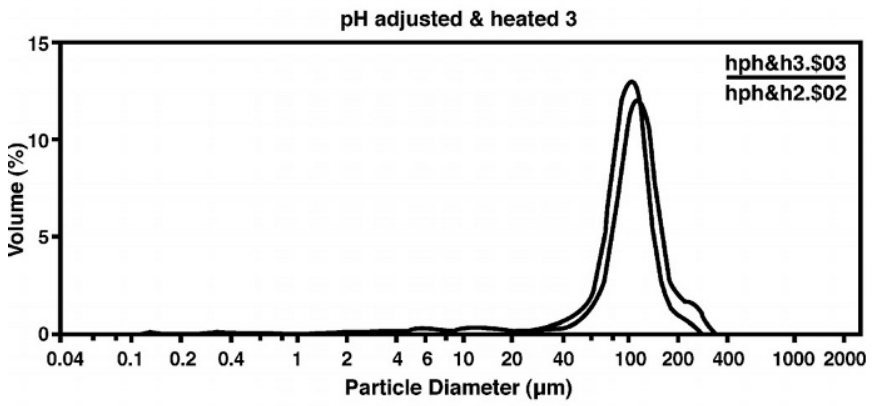

(c)

Figure 3. Particle size distribution of the precipitates formed by a) heating, b) $\mathrm{pH}$ adjustment and c) $\mathrm{pH}$ adjustment and heating of the permeates for two replications.

$\mathrm{pH}$-adjusted permeates and heat-treated permeates, respectively. The lactose contents of the skim milk, permeates, and the treated permeates for the laboratory-scale experiments are shown in Figure 5. There was no marked change in the lactose concentration of the permeates as a result of any of the three treatments followed by refiltration. Thus a simultaneous reduction of lactose and retention of calcium could be achieved by a two-step ultrafiltration process. Additionally, removal of calcium from the permeate can improve the purity and quality of lactose produced subsequently (Kelly et al., 1993). There was about a $21 \%$ decrease in the total nitrogen in the permeate after $\mathrm{pH}$ adjustment or $\mathrm{pH}$ adjustment and heating,

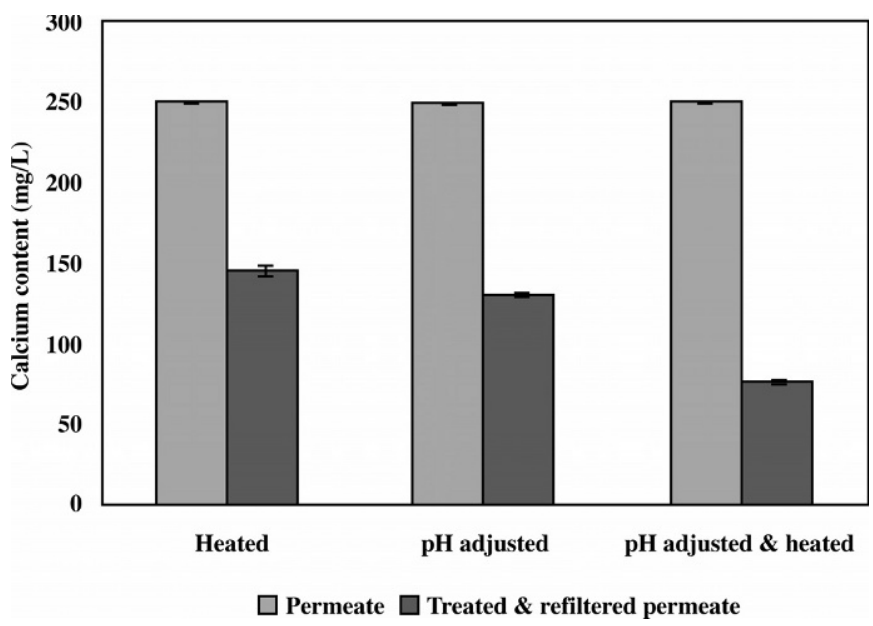

Figure 4. Decrease in calcium content due to different treatments and refiltration of the permeates during the laboratory-scale experiments.

when followed by refiltering. This could be due to the removal of some peptides from the permeate. If so, this may further improve the purity and quality of lactose produced subsequently. This method does not alter the native state of proteins as it involves treatment of ultrafiltrate that contains only minerals and lactose from milk.

The applicability of this developed process was checked at the pilot-scale, also. The separation performances of laboratory-scale and pilot-scale ultrafiltration membranes for the first stage can be seen in Table 2 . The performance of the process with respect to calcium recovery and lactose removal at pilot scale is compared with the laboratory-scale performance in

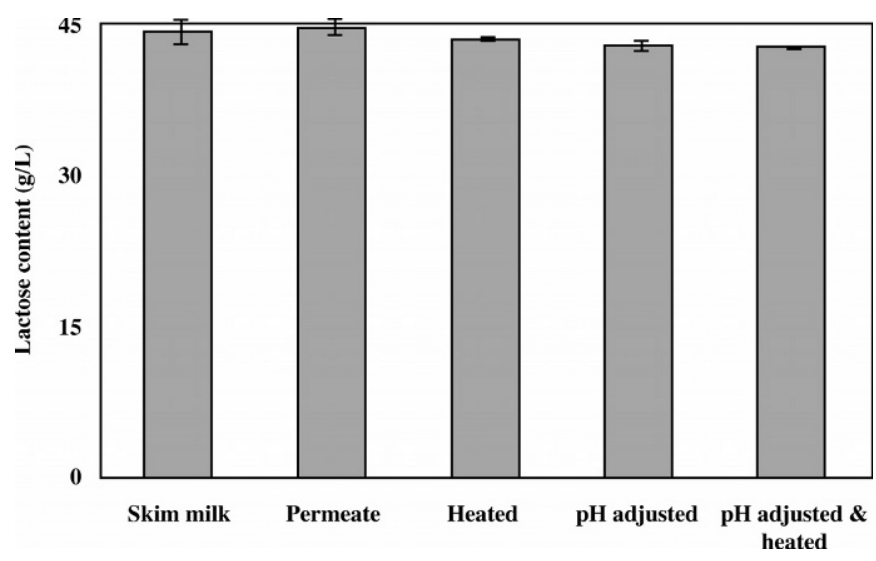

Figure 5. Lactose concentration in skim milk, permeates, and treated and refiltered permeates during laboratory-scale experiments. 


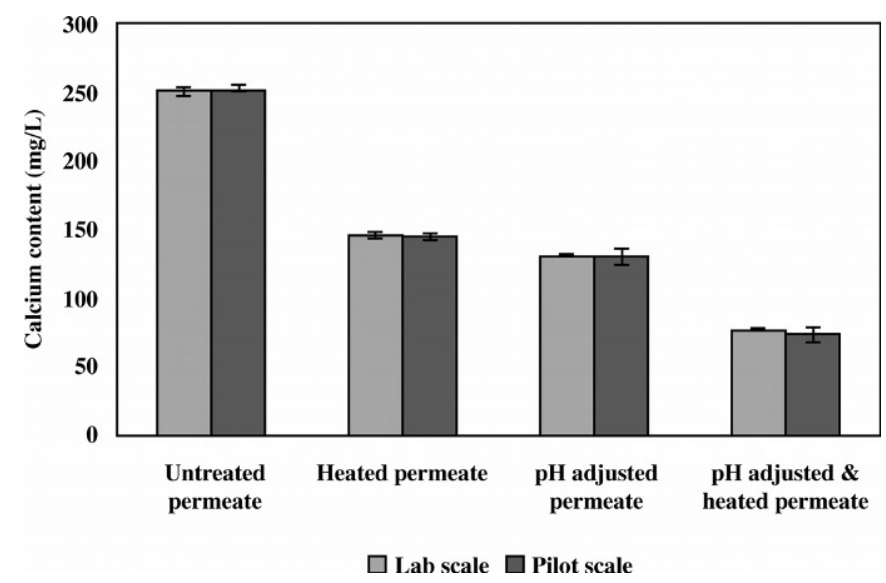

Figure 6. Comparison of decrease in calcium content due to different treatments and refiltration of the permeates between the laboratory- and the pilot-scale experiments.

Figures 6 and 7, respectively. The process performance at laboratory and pilot scale was very similar considering the composition of the permeates resulting from the first stage of $4 \times$ concentration as well as calcium recovery and lactose reduction levels. Thus, the developed process was successfully applied to the pilot scale. Although not evaluated in the present study, this process could be applied for calcium recovery during ultrafiltration of other products such as whole milk, whey, and buttermilk. The recovered calcium using this process could be incorporated back in the retentate to improve the calcium recovery or could be used in calcium supplement or calcium fortification type applications.

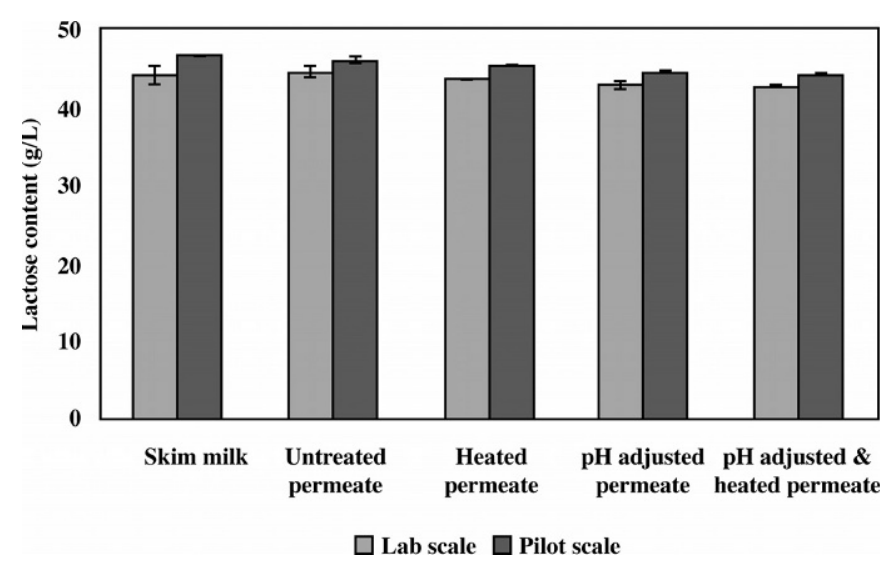

Figure 7. Comparison of lactose concentration in skim milk, permeates, and treated and refiltered permeates between laboratoryand pilot-scale experiments.

\section{CONCLUSIONS}

About $76 \%$ of the total lactose and about $16 \%$ of the total calcium present permeated through the $10-\mathrm{kDa}$ membrane during $4 \times$ concentration of the skim milk. The permeates when refiltered after heat treatment, $\mathrm{pH}$ adjustment, and a combination of these two, $\sim 42$, $\sim 50$, and $\sim 70 \%$ of the calcium present was retained. There was no marked effect of these treatments and refiltration of the permeates on the lactose removal. This process of recovering calcium during lactose reduction by ultrafiltration does not affect the native state of any of the milk proteins. A combination of $\mathrm{pH}$ adjustment and heat treatment to the permeate followed by refiltration proved the best method for calcium recovery and has a potential for the industrial applications.

\section{ACKNOWLEDGMENTS}

We would like to thank Dairy Management Inc., USA, for the financial support and Department of Soil Science, California Polytechnic State University, for the access to the atomic absorption spectrophotometer.

\section{REFERENCES}

Brooks, I. B., G. A. Luster, and D. B. Easterly. 1970. A procedure for rapid determination of the major cations in milk by atomic absorption spectrophotometry. At. Absorpt. Newsl. 9, 93.

Cheryan, M. 1986. Ultrafiltration Handbook. Technomic Pub., Lancaster, PA.

Edelsten, D., M. Meersohn, P. Friis, E. W. Nielsen, K. L. Sørensen, and E. Gudmand-Høyer. 1983. Production of skim milk powder with lactose content reduced by ultrafiltration. Milchwissenschaft 38:261-263.

Kelly, P. M., B. S. Horton, and H. Burling. 1993. Partial demineralization of whey by nanofiltration. Int. Dairy Fed. Bull. 9201:130-140.

Kleyn, D. H., and J. R. Trout. 1984. Enzymatic-ultraviolet method for measuring lactose in milk: Collaborative study. J. Assoc. Off. Anal. Chem. 67:637-640.

Kosikowski, F. V. 1979. Low lactose yogurts and milk beverages by ultrafiltration. J. Dairy Sci. 62:41-46.

Mahoney, R. R. 1992. Lactose: Enzymatic modification. Pages 75125 in Advanced Dairy Chemistry. Vol. 3. Lactose, Water, Salts, and Vitamins. P. F. Fox, ed. Chapman \& Hall, New York.

Martley, F. G., and V. L. Crow. 1993. Interactions between nonstarter microorganisms during cheese manufacture and ripening. Int. Dairy J. 3:461-484.

Patel, R. S., H. Reuter, D. Prokopek, and S. Sachdeva. 1991. Manufacture of low lactose powder using ultrafiltration technology. Food Sci. Technol. 24:338-340.

Premaratne, R. J., and M. A. Cousin. 1991. Changes in the chemical composition during ultrafiltration of skim milk. J. Dairy Sci. 74:788-795.

Ramchandra Rao, H. G., M. J. Lewis, and A. S. Grandison. 1995. Effect of $\mathrm{pH}$ on flux during ultrafiltration of sweet whey and buttermilk. J. Dairy Res. 62:441-449. 
Silva, T. J. P., A. J. R. daPinherio, and D. T. Coelho. 1984. Using $\beta$-galactosidase in the continuous production of homogenized doce de leite. Rev. Inst. Lactinios Candido Tostes 30:19-30. (cited from Mahoney 1992).

St-Gelais, D., S. Hache, and M. Gros-Louis. 1992. Combined effect of temperature, acidification and diafiltration of composition of skim milk retentate and permeate. J. Dairy Sci. 75:1167-1172.

Troy, H. C., and P. F. Sharp. 1930. Alpha and beta lactose in some milk products. J. Dairy Sci. 13:140-157.
Tumerman, L., H. Fram, and K. W. Cornely. 1954. The effect of lactose crystallization on protein stability in frozen concentrated milk. J. Dairy Sci. 37:830-839.

Vasiljevic, T., and P. Jelen. 1999. Temperature effect on behavior of minerals during ultrafiltration of skim milk and acid whey. Milchwissenschaft 54:243-246.

Walstra, P., and R. Jenness. 1984. Salts. Pages 42-57 in Dairy Chemistry and Physics. Wiley \& Sons, New York. 